\title{
Effects of Iron Supplementation on Erythropoietic Response in Patients with Cancer-Associated Anemia Treated by Means of Erythropoietic Stimulating Agents
}

\author{
Torbjörn Karlsson \\ Department of Hematology, Uppsala University Hospital, 75185 Uppsala, Sweden \\ Correspondence should be addressed to Torbjörn Karlsson, torbjorn.a.karlsson@akademiska.se \\ Received 5 June 2011; Accepted 25 July 2011 \\ Academic Editors: L. Catalano and H.-M. Tsai \\ Copyright (c) 2011 Torbjörn Karlsson. This is an open access article distributed under the Creative Commons Attribution License, \\ which permits unrestricted use, distribution, and reproduction in any medium, provided the original work is properly cited.

\begin{abstract}
During the past decade, intravenous iron supplementation to ESA (erythropoiesis-stimulating agent) therapy has emerged as an option to augment hemoglobin response in anemic cancer patients. In this paper, the results of seven published randomized clinical trials assessing the role of iron supplementation to ESA therapy in the hematology/oncology setting will be discussed. The pathogenetic mechanisms behind functional iron deficiency, a major reason for ESA hyporesponsiveness in cancer, will also be described.
\end{abstract}

\section{Introduction}

Recombinant human erythropoietin (rHuEPO) has revolutionized the treatment of anemia associated with chronic kidney disease (CKD). A few years after the publication of the trial on rHuEPO treatment in the nephrology setting by Eschbach and coworkers [1], reports on ESA treatment of anemia associated with solid tumors as well as hematologic malignancies were published [2-4]. Although epoetin and darbepoetin alfa treatment of such patients increases hemoglobin, reduces transfusion requirements, relieves symptoms of anemia, and improves health-related quality of life [5-8], the efficacy is less than that in the nephrology setting with hemoglobin responses (defined as an increase in $\mathrm{Hb}>20 \mathrm{~g} / \mathrm{L}$, or $\mathrm{Hb}$ increased to $120 \mathrm{~g} / \mathrm{L}$ or more) typically about $60 \%[6,9-11]$.

A major reason why anemic cancer patients do not respond to ESAs is functional iron deficiency (FID), that is, failure to provide erythropoiesis with iron despite sufficient iron stores. The mechanism behind FID has been elucidated in recent years $[12,13]$. An inflammatory response induced by conditions such as cancer increases the expression of the hepatic protein hepcidin in an interleukin-6-dependent manner [14]. Secreted hepcidin binds to the transmembrane iron-transporting protein ferroportin in macrophages of the reticuloendothelial system (RES) as well as in hepatocytes and in enterocytes and downregulates its expression by posttranslational mechanisms [15]. In addition to decreased transport of iron from enterocytes to the circulation, the downregulated ferroportin expression reduces iron efflux from macrophages $[16,17]$, thus making less iron available for erythropoiesis, the ultimate consequence of which is FID and anemia [18]. FID has also been observed in CKD patients treated with ESAs [19]. This variant of FID can occur without any inflammatory response with iron blockage in macrophages and hepatocytes, but the underlying mechanism is an ESA-driven supraphysiological erythropoiesis in which the rate-limiting step is the delivery of iron from its stores to erythroblasts. One way to avoid the relative iron deficiency in FID is the addition of intravenous (i.v.) iron to ESA therapy, which has been found effective in the nephrology setting [19]. It has also been shown that i.v. iron alone raises $\mathrm{Hb}$ in anemic CKD patients with FID [20].

For noninvasive diagnosis of FID, the combination of more than $100 \mu \mathrm{g} / \mathrm{L}$ ferritin and less than $20 \%$ transferrin saturation (TSAT) has been proposed [19, 21]. Although the diagnosis of absolute or functional iron deficiency is straightforward to diagnose in otherwise healthy individuals, it is often more difficult to diagnose in patients who suffer from cancer, infections, or inflammatory diseases since the 
biochemical iron status is affected by acute-phase responses [22]. Under these circumstances, the best way to assess the iron status of an individual is to perform a bone marrow iron staining [23]. Thus, in the hematology setting where bone marrow examination is routinely performed, the optimal definition of FID is probably a positive bone marrow iron staining in combination with TSAT $<20 \%$.

The current American and European hematology/oncology guidelines recommend i.v. iron supplementation to cancer patients on ESA therapy with iron deficiency [24] and absolute or functional iron deficiency [25], respectively, but do not consider i.v. iron supplementation as a care standard in this setting. In this paper, I will focus on the seven published randomized clinical trials (RTCs) assessing the role of iron supplementation in cancer patients on ESA therapy [26-32].

\section{Characterization of Study Subjects, ESA, and Iron Doses as well as Preparations}

These seven RCTs were published between 2004 and 2011 and include a total of 1703 patients, the largest reporting the results for 502 and the smallest for 67 patients [28, 32]. The type of ESA used was darbepoetin in four of the trials and Epo alfa or Epo beta in the other three. No increase in ESA dose was allowed in the trials by Auerbach, Bastit and Steensma, whereas ESA dose escalation was permitted in the other three trials if no $\mathrm{Hb}$ increment of at least $1 \mathrm{~g} / \mathrm{dL}$ was seen after 4 weeks of treatment $[27,28,30]$. ESA dose reduction was allowed in all but one of the trials [26]. Six of the trials excluded patients with absolute iron deficiency, but only the Hedenus trial used positive bone marrow iron staining as an inclusion criterion [28]. The other 5 trials used different cut-off points for ferritin and TSAT to exclude patients with an absolute iron deficiency (Table 1). The Auerbach trial in 2004 probably included patients with an absolute iron deficiency since one inclusion criterion was ferritin $\leq 200 \mu \mathrm{g} / \mathrm{L}$ or $<300 \mu \mathrm{g} / \mathrm{L}$ with transferrin saturation $\leq 19 \%[26]$.

Ferric gluconate was used as iron preparation in 4 of the trials, iron dextran in 2, and iron sucrose in one. The cumulative dose of intravenous iron in the trials differed at least four-fold, from $750 \mathrm{mg}$ per patient (protocol) in the Pedrazzoli trial [30] to $3000 \mathrm{mg}$ (administered) in the 2004 trial by Auerbach [26]. Iron was withheld in 4 of the studies if there were biochemical signs of iron overload [28-31]. The trial by Hedenus and coworkers [28] included patients with lymphoproliferative malignancies not receiving chemotherapy only, whereas the other six trials involved anemic patients with solid malignancies, the most common being breast, gastrointestinal, and lung cancers, as well as patients with hematologic malignancies on concomitant chemotherapy.

\section{Summary of Results}

In six of the RCTs discussed here, there was a significantly greater increase in $\mathrm{Hb}$ and/or a greater proportion of patients who achieved a hemoglobin response (defined as an increase in $\mathrm{Hb}>20 \mathrm{~g} / \mathrm{L}$ or $\mathrm{Hb}$ increase to $120 \mathrm{~g} / \mathrm{L}$ or more or in the 2010 Auerbach trial target $\mathrm{Hb} \geq 110 \mathrm{~g} / \mathrm{L}$ ) in ESA plus i.v. iron-treated patients (experimental population) compared to those treated with ESA plus oral iron or no iron (control population). Among the six trials with positive results, the increase in $\mathrm{Hb}$ varied from 19 to $29 \mathrm{~g} / \mathrm{L}$ in the experimental populations compared to 9 to $16 \mathrm{~g} / \mathrm{L}$ in the controls [26-31], whereas, in the Steensma trial, the increment in $\mathrm{Hb}$ was 26 and $24 \mathrm{~g} / \mathrm{L}$ in the experimental and the control populations, respectively, with no significant difference between them [32]. The hemoglobin response in the six positive trials varied from 68 to 93 percent in the experimental populations compared to 25 to 73 percent in controls. In five of the trials, the time to achieve a hemoglobin response was significantly shorter in the experimental populations [26, 28-31]. In the Steensma trial, the hemoglobin responses in the experimental and control populations were 70 and $65 \%$, respectively, a nonsignificant difference. Two of the trials reported that a significant greater proportion of patients with FID (TSAT < 20\%) receiving intravenous iron supplementation achieved a hemoglobin response compared to those with TSAT $>20 \%[27,28]$. In all trials reporting EOTP (end of treatment period) ferritin or change in ferritin during treatment, ferritin decreased or increased less in controls compared to the experimental populations (Table 2). Absence of intravenous iron supplementation led to decreased EOTP TSAT compared to baseline in 3 of these trials, whereas this was not observed in the Steensma trial [32]. The Hedenus and Steensma trials assessed a possible ESA saving effect of iron supplementation, although cumulative ESA doses per patient did not differ significantly between the experimental and the control populations [28, 32]. The fraction of patients receiving transfusions with red blood cells varied from 1 to $25 \%$ in the trials, with one of them showing a significantly reduced need for transfusions in the experimental population compared to control [29]. Quality of life (QoL) was assessed in four of the trials, but no significant positive effects could be detected when comparing the experimental and the control populations $[26,29,31,32]$, whereas there was a positive correlation between $\mathrm{Hb}$ increment and positive effects on QoL in the trials by Auerbach and Steensma irrespective of treatment group $[26,32]$. A suspected higher incidence of severe adverse events in the i.v. iron population in the Steensma trial [32] led to its premature termination, whereas acute adverse events including fatigue, myalgia, and nausea reported in the other trials were mild, except for 2 cases of iron-related anaphylactic reactions in the Auerbach 2010 trial [31].

\section{Discussion}

Although it has been known for many years that i.v. iron supplementation to ESA therapy can augment hemoglobin response in the nephrology setting $[33,34]$, the first trial showing an increased hemoglobin response due to iron supplementation in anemic cancer patients on ESA therapy was not published until 2004 [26]. The results of that trial 
TABLe 1: Eligibility criteria (Hb, ferritin, TSAT, bone marrow iron staining) for the seven trials.

\begin{tabular}{|c|c|c|c|c|}
\hline Trial & $\mathrm{Hb}(\mathrm{g} / \mathrm{L})$ & Ferritin $(\mu \mathrm{g} / \mathrm{L})$ & TSAT $(\%)$ & BM iron \\
\hline Auerbach 2004 [26] & $\leq 105$ & $\leq 200$ & $\leq 19^{*}$ & ND \\
\hline Auerbach 2010 [31] & $\leq 100$ & $\geq 10$ & $\geq 15$ & ND \\
\hline Bastit et al. [29] & $<110$ & $10-800$ & $\geq 15$ & ND \\
\hline Hedenus et al. [28] & $90-110$ & $<800$ & - & + \\
\hline Henry et al. [27] & $<110$ & $100-900$ & $15-35$ & ND \\
\hline Pedrazzoli et al. [30] & $<110$ & $100-800$ & $20-40$ & ND \\
\hline Steensma et al. [32] & $<110$ & $\geq 20$ & $<60$ & ND \\
\hline
\end{tabular}

${ }^{*}$ in combination with ferritin $<300 \mu \mathrm{g} / \mathrm{L}$. Abbreviations: TSAT, transferrin saturation; ND, not determined; BM iron, bone marrow iron staining; + , positive bone marrow iron staining.

TABLE 2: Hemoglobin response (hemoglobin increase $>20 \mathrm{~g} / \mathrm{L}$ or to $\geq 120 \mathrm{~g} / \mathrm{L}$; in the 2010 Auerbach trial target Hb $\geq 110 \mathrm{~g} / \mathrm{L}$ ), EOTP ferritin, and EOTP TSAT for the seven published RCTs comparing ESA \pm iron supplementation.

\begin{tabular}{lccc}
\hline Trial & Hemoglobin response $(\%)$ & EOTP ferritin $(\mu \mathrm{g} / \mathrm{L})$ & EOTP TSAT $(\%)$ \\
\hline Auerbach 2004 [26] & $25 / 36 / 68 / 68^{\mathrm{a}}$ & $\mathrm{NR}$ & NR \\
Auerbach 2010 [31] & $72 / 82^{\mathrm{b}}$ & $50 / 539^{\mathrm{d}}$ & $-0.4 / 6.7^{\mathrm{d}}$ \\
Bastit et al. [29] & $73 / 86^{\mathrm{b}}$ & $\mathrm{NR}$ & $\mathrm{NR}$ \\
Hedenus et al. [28] & $53 / 93^{\mathrm{b}}$ & $112 / 400^{\mathrm{b}}$ & $20 / 30^{\mathrm{b}}$ \\
Henry et al. [27] & $41 / 45 / 73^{\mathrm{c}}$ & $-96 /-14 / 344^{\mathrm{e}}$ & $-14 /-2.7 /-1.8^{\mathrm{e}}$ \\
Pedrazzoli et al. [30] & $70 / 93^{\mathrm{b}}$ & $\mathrm{NR}$ & $\mathrm{NR}$ \\
Steensma et al. [32] & $65 / 67 / 70^{\mathrm{c}}$ & $372 / 426 / 726^{\mathrm{c}}$ & $24 / 28 / 24^{\mathrm{c}}$ \\
\hline
\end{tabular}

${ }^{\mathrm{a}}$ control/p.o. iron/bolus doses iron/total dose infusion iron; ${ }^{\mathrm{b}}$ control/i.v. iron; ${ }^{\mathrm{c}}$ control/p.o. iron/i.v. iron; ${ }^{\mathrm{d}}$ mean change control/i.v. iron; ${ }^{\mathrm{e}}$ mean change control/p.o. iron/i.v. iron. Abbreviations: EOTP, end of treatment period; TSAT, transferrin saturation; NR, not reported; i.v., intravenous.

have been confirmed by five other RCTs [27-31]. Previous trials including anemic cancer patients treated with ESAs have shown a typical hemoglobin response of about $60 \%$ $[6,9-11]$, a figure that increased significantly to $68-93 \%$ when ESA was supplemented with i.v. iron [26-31]. In contrast to the other six trials, the results of the Steensma trial [32] revealed no improvement in hemoglobin response after addition of i.v. iron to ESA therapy. There are several possible explanations for this lack of effect, two of which will be discussed here. Firstly, the Steensma trial included subjects with a TSAT of up to $60 \%$. This inclusion criterion meant that patients with neither absolute nor functional iron deficiency, that is, patients less likely to benefit from iron supplementation, could be included. Furthermore, the dose of iron in the Steensma trial might have been too low to be efficient. The planned total dose of iron in this trial was the second lowest among the seven published trials, and the mean actual dose administered was the lowest [35]. In two of the trials, the hemoglobin response in the control populations was lower than expected, 25 and $41 \%$, respectively, probably due to the shorter duration of these trials $[26,27]$ and that patients with absolute iron deficiency were not excluded [26]. The lowest efficient iron dose in these trials was $750 \mathrm{mg}$ administered over 6 weeks [30].

Although there are many hematological and non-hematological benefits of iron [36], there are also safety concerns about iron supplementation. The most feared acute side effect of intravenous iron administration is the risk of anaphylactic reactions associated with iron dextran preparations. However, in the nephrology setting, the risk of acute severe adverse reactions after iron dextran administration is less than 1\% [37]. The risk of anaphylaxis is even smaller with modern iron preparations $[38,39]$. In agreement with this, the reported incidence of acute severe adverse reactions associated with intravenous iron in the RCTs discussed here was well below $1 \%$.

Two of the major concerns about long-term intravenous iron supplementation are the increased risks of bacterial infections and vascular damage induced by oxidative stress. It is known from the pre-rHuEPO era that heavily transfused CKD patients with biochemical signs of iron overload were at higher risk of bacterial infections [40, 41]. However, the epidemiological survey EPIBACDIAL performed after the advent of rHuEPO treatment could not identify elevated serum ferritin levels as a risk factor for bacterial infections in CKD patients [42]. The risk of iron overload after multiple iron infusions may be prevented by repeated measurements of ferritin and suspension from the infusions if biochemical signs of iron accumulation are observed [19]. The other major concern is that iron supplementation may accelerate atherosclerosis by oxidative stress, thereby increasing the risk of renal and cardiovascular morbidity [43, 44]. Intravenous iron administration in CKD patients leads to a rapid increase of nontransferrin bound redox-active iron and induces oxidative stress measured as an increase in lipid peroxidation $[45,46]$. Since the oxidative stress induced by the different commercially available i.v. iron preparations does not seem to be of similar magnitude [47], it may be possible to reduce this risk by choosing one of the more stable ones. 
At least in theory, iron administration may decrease iron mobilization from its stores in FID, since diferric holotransferrin but not apotransferrin stimulates hepcidin expression [48]. However, a possible iron-induced hepcidinmediated increased sequestration of iron in the RES must be disregarded due to its positive effects in FID since i.v. administered iron actually stimulates erythropoiesis in this condition. In absolute iron deficiency, i.v. administrated iron-carbohydrates rapidly enter RES macrophages, where they are processed, thus releasing iron from these cells and delivering it to erythroblasts by transferrin. In cancer patients, less iron may be delivered from the RES macrophages to erythroblasts $[49,50]$. Since a fraction of iron in the iron-carbohydrate complex directly binds transferrin [51], it is possible that this fraction, which escapes sequestration in RES, mediates its biological effect in FID.

\section{Concluding Remarks}

Six of the seven RCTs discussed here show an augmented erythropoietic response in anemic ESA-treated cancer patients receiving i.v. iron supplementation compared to those not receiving iron. This effect was observed in patients with absolute iron deficiency, those who fulfilled the FID criteria as well as in those who did not.

Intravenous iron supplementation should be strongly considered in anemic cancer patients treated with ESAs, since its positive effect on hemoglobin response has been documented in six published RCTs [26-31], two RCTs in abstract form [52, 53], and two meta-analyses [54, 55]. However, the preferred iron preparation, optimal dose of iron, and dosing schedule are currently not known.

\section{Conflict of Interests}

The authors declare that they have no conflict of interests.

\section{References}

[1] J. Eschbach, M. Kelly, N. Haley, R. Abels, and J. Adamson, "Treatment of the anemia of progressive renal failure with recombinant human erythropoietin," New England Journal of Medicine, vol. 321, no. 3, pp. 158-163, 1989.

[2] R. I. Abels, "Use of recombinant human erythropoietin in the treatment of anemia in patients who have cancer," Seminars in Oncology, vol. 19, no. 3, supplement 8, pp. 29-35, 1992.

[3] J. L. Spivak, "The application of recombinant erythropoietin in anemic patients with cancer," Seminars in Oncology, vol. 19, no. 3, supplement 8, pp. 25-28, 1992.

[4] H. Ludwig, E. Fritz, H. Kotzmann, P. Hocker, H. Gisslinger, and U. Barnas, "Erythropoietin treatment of anemia associated with multiple myeloma," New England Journal of Medicine, vol. 322, no. 24, pp. 1693-1699, 1990.

[5] M. Cazzola, D. Messinger, V. Battistel et al., "Recombinant human erythropoietin in the anemia associated with multiple myeloma or non-Hodgkin's lymphoma: dose finding and identification of predictors of response," Blood, vol. 86, no. 12, pp. 4446-4453, 1995.

[6] A. Österborg, M. A. Boogaerts, R. Cimino et al., "Recombinant human erythropoietin in transfusion-dependent anemic patients with multiple myeloma and non-Hodgkin's lymphoma-a randomized multicenter study," Blood, vol. 87, no. 7, pp. 2675-2682, 1996.

[7] G. D. Demetri, M. Kris, J. Wade, L. Degos, and D. Cella, "Quality-of-life benefit in chemotherapy patients treated with epoetin alfa is independent of disease response or tumor type: results from a prospective community oncology study," Journal of Clinical Oncology, vol. 16, no. 10, pp. 3412-3425, 1998.

[8] M. R. Nowrousian, "Recombinant human erythropoietin in the treatment of cancer-related or chemotherapy-induced anaemia in patients with solid tumours," Medical Oncology, vol. 15, no. 1, pp. S19-S28, 1998.

[9] J. Vansteenkiste, R. Pirker, B. Massuti et al., "Double-blind, placebo-controlled, randomized phase III trial of darbepoetin alfa in lung cancer patients receiving chemotherapy," Journal of the National Cancer Institute, vol. 94, no. 16, pp. 1211-1220, 2002.

[10] M. Hedenus, M. Adriansson, J. San Miguel et al., "Efficacy and safety of darbepoetin alfa in anaemic patients with lymphoproliferative malignancies: a randomized, double-blind, placebo-controlled study," British Journal of Haematology, vol. 122, no. 3, pp. 394-403, 2003.

[11] Y. Ichinose, T. Seto, Y. Nishiwaki et al., "Randomized phase 2 dose-finding study of weekly administration of darbepoetin alfa in anemic patients with lung or ovarian cancer receiving multicycle platinum-containing chemotherapy," Japanese Journal of Clinical Oncology, vol. 40, no. 6, pp. 521-529, 2010.

[12] C. N. Roy and N. C. Andrews, "Anemia of inflammation: the hepcidin link," Current Opinion in Hematology, vol. 12, no. 2, pp. 107-111, 2005.

[13] E. Nemeth and T. Ganz, "Hepcidin and iron-loading anemias," Haematologica, vol. 91, no. 6, pp. 727-732, 2006.

[14] E. Nemeth, S. Rivera, V. Gabayan et al., "IL-6 mediates hypoferremia of inflammation by inducing the synthesis of the iron regulatory hormone hepcidin," Journal of Clinical Investigation, vol. 113, no. 9, pp. 1271-1276, 2004.

[15] E. Nemeth, M. S. Tuttle, J. Powelson et al., "Hepcidin regulates cellular iron efflux by binding to ferroportin and inducing its internalization," Science, vol. 306, no. 5704, pp. 2090-2093, 2004.

[16] L. Viatte, G. Nicolas, D. Q. Lou et al., "Chronic hepcidin induction causes hyposideremia and alters the pattern of cellular iron accumulation in hemochromatotic mice," Blood, vol. 107, no. 7, pp. 2952-2958, 2006.

[17] S. Rivera, L. Liu, E. Nemeth, V. Gabayan, O. E. Sorensen, and T. Ganz, "Hepcidin excess induces the sequestration of iron and exacerbates tumor-associated anemia," Blood, vol. 105, no. 4, pp. 1797-1802, 2005.

[18] D. A. Weinstein, C. N. Roy, M. D. Fleming, M. F. Loda, J. I. Wolfsdorf, and N. C. Andrews, "Inappropriate expression of hepcidin is associated with iron refractory anemia: implications for the anemia of chronic disease," Blood, vol. 100, no. 10, pp. 3776-3781, 2002.

[19] F. Locatelli, P. Barany, B. Canaud et al., "European Best Practice Guidelines Working Group. Revised European best practice guidelines for the management of anaemia in patients with chronic renal failure," Nephrology Dialysis Transplantation, vol. 19, supplement 2, pp. 1-47, 2004.

[20] G. Mirescu, L. Garneata, C. Capusa, and N. Ursea, "Intravenous iron supplementation for the treatment of anaemia in pre-dialyzed chronic renal failure patients," Nephrology Dialysis Transplantation, vol. 21, no. 1, pp. 120-124, 2006.

[21] D. H. Henry, "Supplemental iron: a key to optimizing the response of cancer-related anemia to rHuEPO?" Oncologist, vol. 3, no. 4, pp. 275-278, 1998. 
[22] M. Woorwood, "Laboratory determination of iron status," in Iron Metabolism in Health and Disease, J. Brock, J. Halliday, M. Pippard, and L. Powell, Eds., pp. 449-476, W. B. Saunders, London. UK, 1994.

[23] A. N. Baer, E. N. Dessypris, and S. B. Krantz, "The pathogenesis of anemia in rheumatoid arthritis: a clinical and laboratory analysis," Seminars in Arthritis and Rheumatism, vol. 19, no. 4, pp. 209-223, 1990.

[24] J. D. Rizzo, M. Brouwers, P. Hurley et al., "American Society of Hematology/American Society of Clinical Oncology clinical practice guideline update on the use of epoetin and darbepoetin in adult patients with cancer," Blood, vol. 116, no. 20, pp. 4045-4059, 2010.

[25] M. S. Aapro and H. Link, "September 2007 update on EORTC guidelines and anemia management with erythropoiesisstimulating agents," Oncologist, vol. 13, no. 3, pp. 33-36, 2008.

[26] M. Auerbach, H. Ballard, J. R. Trout et al., "Intravenous iron optimizes the response to recombinant human erythropoietin in cancer patients with chemotherapy-related anemia," Journal of Clinical Oncology, vol. 22, no. 7, pp. 1301-1307, 2004.

[27] D. H. Henry, N. V. Dahl, M. Auerbach, S. Tchekmedyian, and L. R. Laufmane, "Intravenous ferric gluconate significantly improves response to epoetin alfa versus oral iron or no iron in anemic patients with cancer receiving chemotherapy," Oncologist, vol. 12, no. 2, pp. 231-242, 2007.

[28] M. Hedenus, G. Birgegård, P. Näsman et al., "Addition of intravenous iron to epoetin beta increases hemoglobin response and decreases epoetin dose requirement in anemic patients with lymphoproliferative malignancies," Leukemia, vol. 21, no. 4, pp. 627-632, 2007.

[29] L. Bastit, A. Vandebroek, S. Altintas et al., "Randomized, multicenter, controlled trial comparing the efficacy and safety of darbepoetin alpha administered every 3 weeks with or without intravenous iron in subjects with chemotherapyinduced anemia," Journal of Clinical Oncology, vol. 26, no. 10, pp. 1611-1618, 2008.

[30] P. Pedrazzoli, A. Farris, S. Del Prete et al., "Randomized trial of intravenous iron supplementation in patients with chemotherapy-related anemia without iron deficiency treated with darbepoetin alpha," Journal of Clinical Oncology, vol. 26, no. 10, pp. 1619-1625, 2008.

[31] M. Auerbach, P. T. Silberstein, R. T. Webb et al., "Darbepoetin alfa 300 or $500 \mu \mathrm{g}$ once every 3 weeks with or without intravenous iron in patients with chemotherapy-induced anemia," American Journal of Hematology, vol. 85, no. 9, pp. 655-663, 2010.

[32] D. Steensma, J. Sloan, S. Dakhil et al., "Phase III randomized study of the effect of parenteral iron, no iron, or oral iron supplementation on the erythropoietic response to darbepoetin alfa for patients with chemotherapy-associated anemia," Journal of Clinical Oncology, vol. 29, no. 1, pp. 97-105, 2011.

[33] S. Fishbane, G. L. Frei, and J. Maesaka, "Reduction in recombinant human erythropoietin doses by the use of chronic intravenous iron supplementation," American Journal of Kidney Diseases, vol. 26, no. 1, pp. 41-46, 1995.

[34] I. C. Macdougall, B. Tucker, J. Thompson, C. R. V. Tomson, L. R. I. Baker, and A. E. G. Raine, "A randomized controlled study of iron supplementation in patients treated with erythropoietin," Kidney International, vol. 50, no. 5, pp. 1694-1699, 1996.

[35] M. Auerbach, "Intravenous iron failed to improve erythropoietic response in patients with chemotherapy-induced anemia," 2010, http://www.hemonctoday.com/article.aspx?rid=78461.

[36] R. Agarwal, "Nonhematological benefits of iron," American Journal of Nephrology, vol. 27, no. 6, pp. 565-571, 2007.
[37] S. Fishbane, V. D. Ungureanu, J. K. Maesaka, C. J. Kaupke, V. Lim, and J. Wish, "The safety of intravenous iron dextran in hemodialysis patients," American Journal of Kidney Diseases, vol. 28, no. 4, pp. 529-534, 1996.

[38] G. R. Bailie, J. A. Clark, C. E. Lane, and P. L. Lane, "Hypersensitivity reactions and deaths associated with intravenous iron preparations," Nephrology Dialysis Transplantation, vol. 20, no. 7, pp. 1443-1449, 2005.

[39] S. B. Silverstein and G. M. Rodgers, "Parenteral iron therapy options," American Journal of Hematology, vol. 76, no. 1, pp. 74-78, 2004.

[40] M. Kessler, B. Hoen, D. Mayeux, D. Hestin, and C. Fontenaille, "Bacteremia in patients on chronic hemodialysis: a multicenter prospective survey," Nephron, vol. 64, no. 1, pp. 95-100, 1993.

[41] B. Hoen, M. Kessler, D. Hestin, and D. Mayeux, "Risk factors for bacterial infections in chronic haemodialysis adult patients: a multicentre prospective survey," Nephrology Dialysis Transplantation, vol. 10, no. 3, pp. 377-381, 1995.

[42] B. Hoen, A. Paul-Dauphin, D. Hestin, and M. Kessler, "EPIBACDIAL: a multicenter prospective study of risk factors for bacteremia in chronic hemodialysis patients," Journal of the American Society of Nephrology, vol. 9, no. 5, pp. 869-876, 1998.

[43] R. Agarwal, N. Vasavada, N. G. Sachs, and S. Chase, "Oxidative stress and renal injury with intravenous iron-in patients with chronic kidney disease," Kidney International, vol. 65, no. 6, pp. 2279-2289, 2004.

[44] T. Drüeke, V. Witko-Sarsat, Z. Massy et al., "Iron therapy, advanced oxidation protein products, and carotid artery intima-media thickness in end-stage renal disease," Circulation, vol. 106, no. 17, pp. 2212-2217, 2002.

[45] A. K. Salahudeen, B. Oliver, J. D. Bower, and L. J. Roberts, "Increase in plasma esterified F2-isoprostanes following intravenous iron infusion in patients on hemodialysis," Kidney International, vol. 60, no. 4, pp. 1525-1531, 2001.

[46] G. Schaller, B. Scheiber-Mojdehkar, M. Woltz et al., "Intravenous iron increases labile serum iron but does not impair forearm blood flow reactivity in dialysis patients," Kidney International, vol. 68, no. 6, pp. 2814-2822, 2005.

[47] J. Toblli, G. Cao, L. Olivieri, and M. Angerosa, "Comparison of the renal, cardiovascular and hepatic toxicity data of original intravenous iron compounds," Nephrology Dialysis Transplantation, vol. 25, no. 11, pp. 3631-3640, 2010.

[48] L. Lin, E. V. Valore, E. Nemeth, J. B. Goodnough, V. Gabayan, and T. Ganz, "Iron transferrin regulates hepcidin synthesis in primary hepatocyte culture through hemojuvelin and BMP2/4," Blood, vol. 110, no. 6, pp. 2182-2189, 2007.

[49] B. G. Danielson, "Structure, chemistry, and pharmacokinetics of intravenous iron agents," Journal of the American Society of Nephrology, vol. 15, no. 2, pp. S93-S98, 2004.

[50] S. Beshara, J. Sörensen, M. Lubberink et al., "Pharmacokinetics and red cell utilization of $52 \mathrm{Fe} / 59 \mathrm{Fe}$-labelled iron polymaltose in anaemic patients using positron emission tomography," British Journal of Haematology, vol. 120, no. 5, pp. 853-859, 2003.

[51] D. B. Van Wyck, J. Anderson, and K. Johnson, "Labile iron in parenteral iron formulations: a quantitative and comparative study," Nephrology Dialysis Transplantation, vol. 19, no. 3, pp. 561-565, 2004.

[52] R. Bellet, H. Ghazal, M. Flam et al., "A phase III randomized controlled study comparing iron sucrose intravenously (iv) to no iron treatment of anemia in cancer patients undergoing chemotherapy and erythropoietin stimulating agent (ESA) 
therapy," Journal of Clinical Oncology, vol. 25, no. 18, p. 9109, 2007.

[53] Y. Beguin, J. Maertens, B. De Prijck et al., "Darbepoetin-alfa and i.v. iron administration after autologous hematopoietic stem cell transplantation: a prospective randomized multicenter tial," Blood, vol. 112, no. 11, abstract 54, 2008.

[54] A. Gafter-Gvili, B. Rosen-Zvi, L. Vidal, U. Gafter, J. Vansteenkiste, and O. Shpilberg, "Intravenous iron supplementation for the treatment of cancer-related anemiasystematic review and meta-analysis," Blood, vol. 116, no. 21, abstract 4249, 2010.

[55] R. Mhaskar, H. Wao, A. Kumar, B. Miladinovic, and B. Djulbegovic, "Role of iron supplementation to erythropoiesis stimulating agents in the management of chemptherapyinduced anemia in cancer patients: a systematic review and meta-analysis," Blood, vol. 116, no. 21, abstract 2055, 2010. 


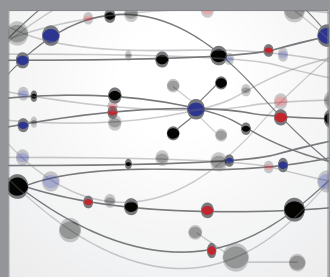

The Scientific World Journal
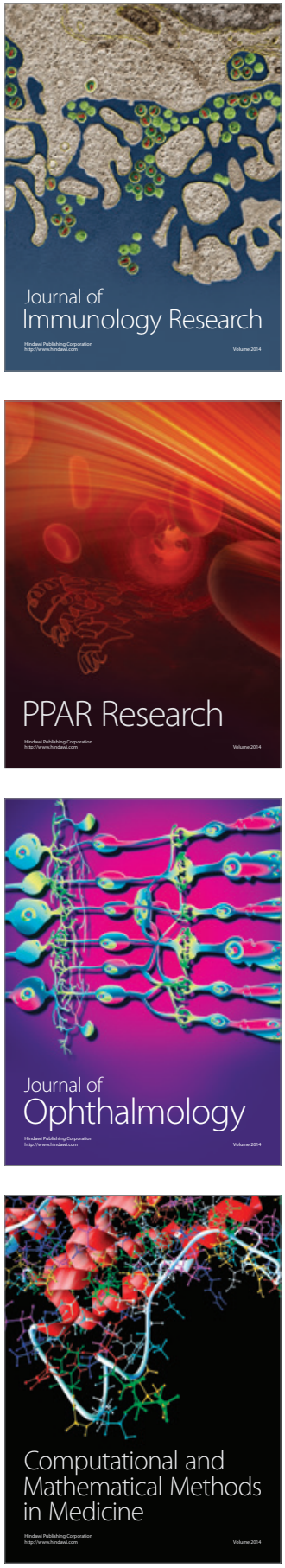

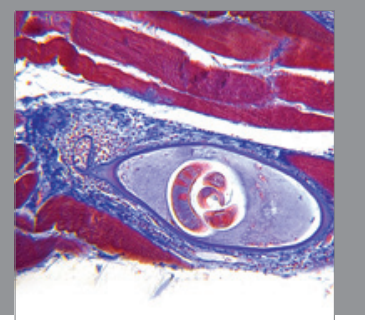

Gastroenterology

Research and Practice
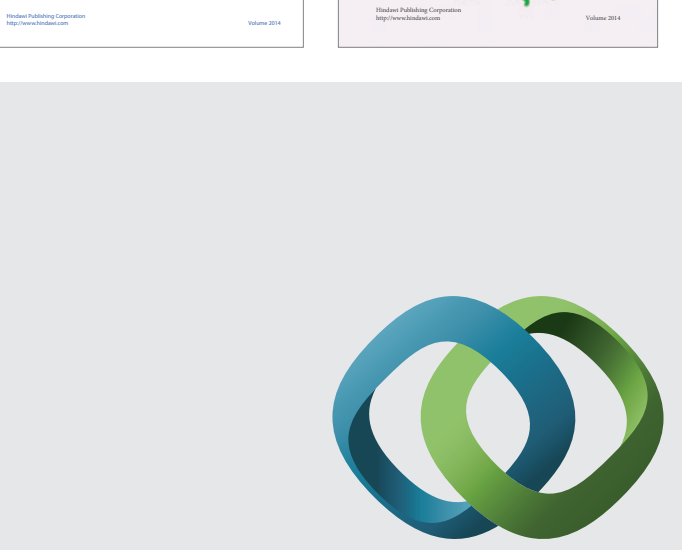

\section{Hindawi}

Submit your manuscripts at

http://www.hindawi.com
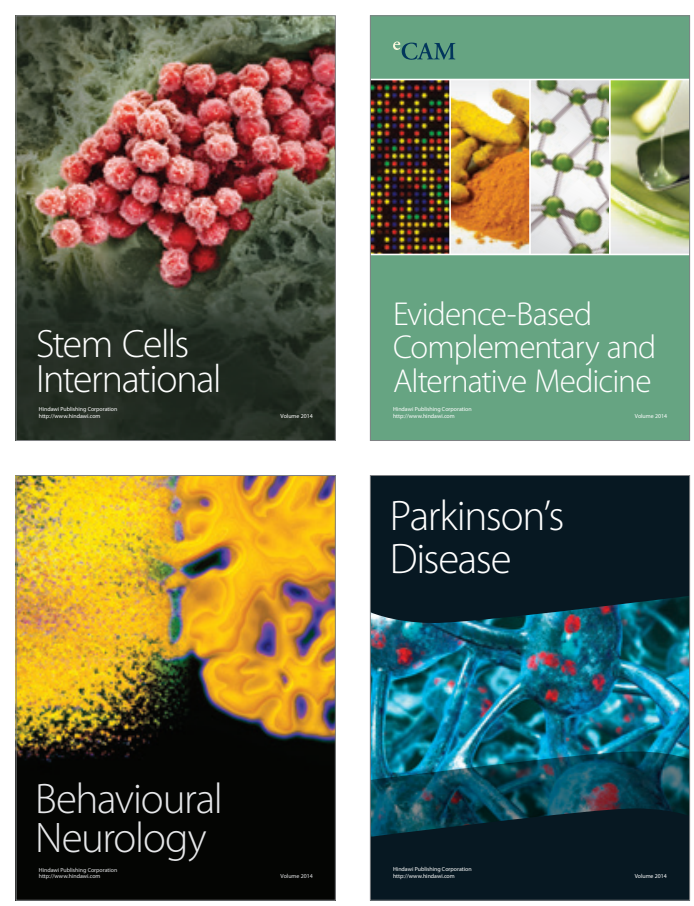

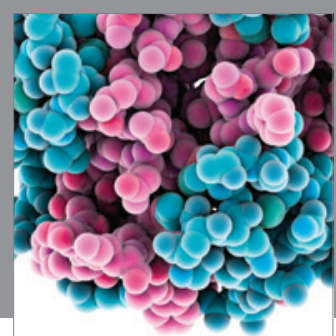

Journal of
Diabetes Research

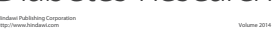

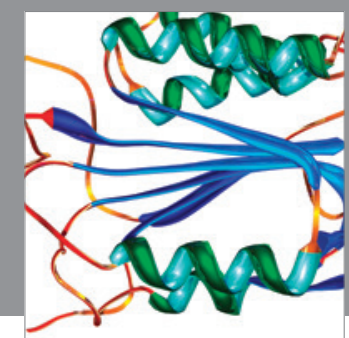

Disease Markers
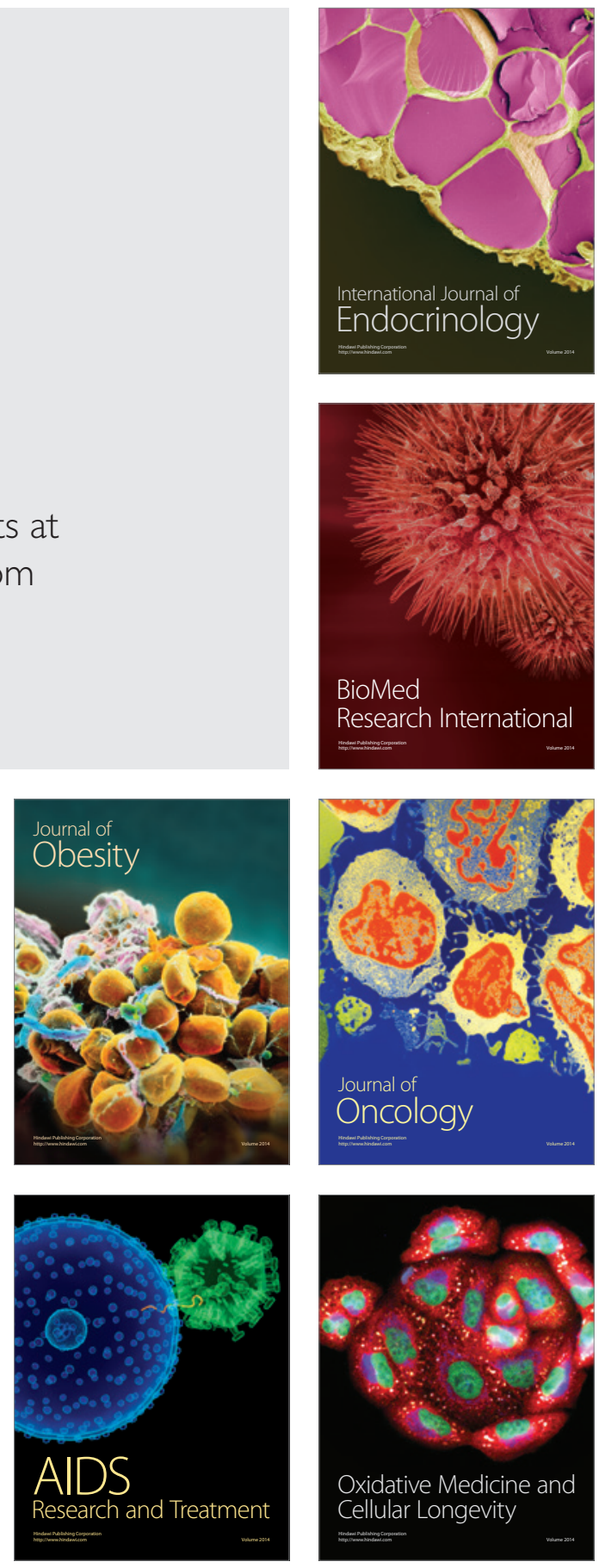